\section{INSTRUCTIONAL TECHNOLOGIES AND SCHOOL CURRICULUM IN NIGERIA: INNOVATIONS AND CHALLENGES}

\author{
JACINTA A. OPARA \\ Senior Research Fellow \\ European School Science Project, Spain
}

\author{
NKASIOBI S. OgUZOR \\ Provost, Federal Collage of Education(Technical) \\ Omoku-Rivers State, Nigeria
}

UDC: $371(32+33)$

Key words: Instructional materials, pedagogy, learners' needs, teacher.

\begin{abstract}
The use of instructional materials in teacher training programs can provide significant input to the overall development of future teachers. Research shows that instructional materials in teacher training help student teachers to establish links between theory and practice by allowing them to make new connections between curriculum topics and the world. The new environment in which colleges develop in Nigeria has made the quality of teaching one of the main concerns and objectives. This paper discusses how to assist teachers in using instructional materials in order to help them to acquire theoretical knowledge, grounded in real practice. The paper attempts to explain the features of instructional materials and how they can assist teachers in planning quality teaching materials.
\end{abstract}

\section{Introduction}

The traditional classroom environment can often neglect factors that are essential for learning. Presently in Nigeria, most learners are taught by the traditional approaches which often place the learners in a passive role. Teachers are therefore compelled by the learner heterogeneity to provide alternative units of instruction and alternative strategies to enable the students to attain educational objectives at their own rate. But the selfefficacy expectations mediate the actual involvement in a particular teaching process. Before a teacher can be expected to operate instructional materials or learn the skills for producing or improvising, it is necessary that such a teacher know and is competent in the usage. So, to be competent, but to also believe in that competence, is a major goal of teacher training.

The above analysis reveals that although a teacher may be encouraged to develop higher order skills amongst student populations such as critical thinking and deep understanding using instructional materials, the issue reminds if he or she is competent. Because of this, the use of instructional materials in educational settings has been subject of much interest in recent years. In this work, instructional materials are presented and described to be used as alternative channels of communication in teaching and learning situation to provide the student teachers with practical and technical preparation for the future.

It is remarkable to note that the teachers are responsible for accomplishing the premises centered on learning with students having a more active role in constructing their knowledge, with complementary learning activities, a more significant tutorial action and instructional materials to support learning. None of these proposals is new in the pedagogical discourse but possibly is not widespread at the colleges of education. In colleges of education teaching methodologies have for centuries been an issue subject to the tradition inherited from generation to generation. Educational innovation at this level is based, in most cases, on individual initiative of each teacher's vision of how should be taught that subject, but it has not been guided by a specific training processes. Indeed the importance of education in any society cannot be understated. It is seen as the single potent factor that leads to the improvement of the individual as well as the society. In this framework, the role and functions of the government becomes important.

In recent years teachers training in information and communication technology (ICT) has become a priority considered a key to enable the incorporation of education to new forms instructional media. The investment in this area for colleges of education is heavy, especially as instrumental training, to manage new information technology tools in teaching and learning processes or as carriers of these processes. To this effect, each colleges of education has launched offers for training in ICT, although no action has been taken generalized as in the case of the level of technological literacy programs targeted these teachers. It is essential to measure the impact of the quality teaching initiatives in order to be able to improve these initiatives. However, assessing the quality of one's teaching remains challenging.

Instructional materials are said to be part of the instructional procedure. Thus, studies have shown that when skills are related to practical situations, attitude and attention improve. Inyang-Abia and Esu (1990) cited in Esu et al. (2004) assert that instructional materials are the pivot on which the wheel of the teaching-learning process rotates. But the use of instructional materials in colleges of education teaching is a complex process conditioned by many variables, which include the level of knowledge the teachers possess about the uses and the related training approaches. Are the teachers prepared to incorporate these instructional materials into their teaching? Do they use these instructional materials already? Do they have sufficient training or need to receive it?

\section{Understanding instructional materials}

Instructional materials are the audio visual materials (software/hardware) which can be used as alternative channels of communication in the teaching-learning process. Instructional materials have been defined by many authors such as Bruner (1973) who stated that the teacher's work as communicator, model and identification figure can be supported by a wise use of variety of 
devices that expand experience, clarify it and give it personal significance.

Obanya (1989) see them as didactic materials - things which are supposed to make teaching and learning possible. According to Agun (1988) they are learning materials, the proper use of which helps learners to learn faster and better. For Johnson (1989) instructional materials are the collections and selection of resources (mechanical, otherwise) from available resources which are applied and integrated into a systematic process of teaching and learning to make learning effective. Ikerionwu (2000) refers to them as objects or devices, which help teacher to make a lesson to the learner. Instructional materials are therefore concrete or physical objects which provide sound, visual or both to the sense organs during teaching (Agina-Obu, 2005).

\section{Dimensions and categories}

Instructional materials are classified under seven categories that specifically include graphic materials, still pictures, projected still pictures, motion pictures including television and video materials, audio materials, 3dimensional materials, computer based instructional programs.

\section{Graphic materials}

Graphic materials serve as concrete channels of information which can help a learner to form a mental picture of what is being communicated (Dike, 1994). These are mainly two-dimensional materials drawn on cardboard paper or on a piece of cloth. They are used to summarize points, to show trends and to highlight relationships in a phenomenon. There are different types of graphic materials namely: charts, graphs, maps and globes, cartoons and comics, posters and billboards, diagrams, sketches, drawings and paintings. There are different types of charts such as simple line chart, time and sequence chart, flip chart, tree chart, stream chart, Gantt chart, flow chart, etc. These charts have unique features, which should determine its appropriateness for a given topic. The teacher must ensure that there is a match between the unique qualities of a chart and the topic.

A simple line chart: has an identifying feature of the two scales known as the axes, placed at right angles to each other; one of the axes represents the vertical axis and the other the horizontal axis. These two axes are used to represent the values of variables under consideration. This could be used to show trends and relationships as well as for a comparative study.

A tree chart looks very much like a tree with a stem and branches. It is analytical in representation. The stem represents the main stock of the family while the branches stand for the offsprings. It could be used to trace genealogy of a family (plants or animals) or an event or the component parts of a phenomenon

A flip/strip chart could also be used to represent a phenomenon with developmental stages. It has many cardboard sheets of the same size with a sequential presentation of each stage. It enhances effective teaching and learning. It can be used to teach topic with topics that have developmental stages.

A time and sequence chart can be used to trace developmental phases or evolution of an event. It depicts the events and their dates of occurrence in a sequential order. It is good for presenting topics with landmark or important dates and events. It can be used to show the contributions of people in a project.

A stream chart: has a synthetical function. It is based on the fact that a river has many tributaries and levels. All the tributaries converge into the main river. These tributaries can be used to represent elements or raw materials needed to produce a particular product.

To illustrate the use to which graphs can be put, there are also other different kinds such as bar graph, circle or pie graph and pictorial graph or pictogram.

A bar graph is a two-scaled graph useful for comparing the magnitude of similar items for showing the relative portions of parts to a whole. It can be used to compress or summarize information about the population of students and teachers in a school. A bar graph is useful in any topic that has component parts with values attached to the each component. The names of the parts are spelled out at the horizontal axis. The values are calculated along the vertical axis. Bars are drawn to reflect the value calculated for each variable.

A pictogram uses diagrammatic representation or self-explanatory symbols to depict an object a product.. It assigns an icon/symbol to a product or phenomenon. Value is as well assigned to each icon. The number of icons can be used to calculate the total quantity of the product.

A circle or pie graph takes the form of a circle subdivided to reveal proportions of parts to whole. The circle resents the total value of a variable which sums up to $100 \%$. Subdivisions of the circle represent proportions of the parts to this total value. It could be used to shows the proportional relationship of parts to whole. It can be used to show the annual budget allocation in various by sectors in the government.

Maps and globes there are three types of maps the physical, political and special purpose maps. A map is a diagrammatic representation of the world on a flat surface. In this, the physical maps reveal the characteristic features of the earth. For example mountains, rivers, oceans, vegetation etc. While the man- made features such as national boundaries, capitals and cities with there news makes the study of the political map of the world a necessity. It is possible to present features like rainfall distribution of a particular area and the population of the people in an area in a special purpose maps. There is possible combination of these maps that are used in physical-political map or a map with the information on cities vegetation, location and rainfall. The teacher can use such maps to lead the class into discovering events, places and population density, though have not visited there feel acquainted with relevant information.

It is possible to show the different forms disasters and their impact on the countries using a physical map to show where these impacts are felt in the country. Ask children to show the impact of air pollution/gas flares on roofing materials (zinc) and on the ozone layer. Show the ozone layer depleting. Show the impact of air pollution as a result of industrial wastes on the Antarctic region with the icebergs melting. Show the effect of this melting on Antarctic region. Show the effect of these melting on aquatic fauna in the Antarctic region. Show the effect of flooding in cities in Europe and Asia and link this with 
mans activities, which cause the depletion of the ozone layer. Use pictures and maps of the world to present these catastrophes.

It is apparent from our discussion of maps and globes that our methodology has shifted towards the use of problem situations and assisting learners to identify resources and come up with their own solutions. The use of multi media approach is also highlighted. We use pictures to highlight where a problem occurred and use a map to show exactly where.

Some graphic materials are used to present information that is they can be presented at the beginning or end a lesson. The well trained teacher seldom begins a lesson with conclusion, to do so is to apply the principles of deductive rather than inductive reasoning. Education psychology has shown that learning is more efficient and productive when it proceeds from the specific to the abstract and general.

\section{Still pictures}

These are photographs taken with the aid of a camera to commemorate important/historical events. After snapping, the negative is developed and a final image is printed on an opaque paper. The functions of still pictures are: to introduce a topic, to demonstrate a process, to enrich and enliven, to practicalize detailed study, recall past events, to correct misconception, to prevent misconception, to create atmosphere, to provide setting, to build background, to explain terminology, to test learning, to test learning, to complete research, to publicize an event, to compare and contrast, to raise questions, to resolve a problem, to develop insight and appreciation, to stimulate reading, to invite participation, to create awareness, to dramatize a point, to develop critical judgment, to form value judgment.

A school does not need to have a photographer or a photographic laboratory before she can select pictures to depict each function in a subject area. This is because experience has shown that still pictures abound in local magazines, almanacs, calendars, and textbooks. Pictures can be obtained from the state ministry of information, the state ministry of education or from the national museum. Our concern should be how to preserve our pictures to enhance usage. This is what mounting techniques should do for us.

Effective picture use can make a lot of difference in a class. It can turn a class from a dull teaching-learning environment to one that is bubbling with activities. This will engender cooperative learning in which the group will first of all organize itself by assigning roles to different members and deciding on procedural rules. Thus a group may decide on how opinions are to be expressed and who acts as the recorder of different opinions. The group agrees on a member to chairman each session and who ensures that nobody has a monopoly of a discussion. What role should a teacher play in this group interaction? A teacher should monitor the group ensuring they are on focus, providing guidance and assistance to ensure that a purpose is attained. It will be apparent that each group will see the same picture differently depending on their frame of reference a model of modern teaching and learning.

There should be a strive to create a resource center where instructional materials on different subjects are kept or produced/improvised for use by teachers for group and individualized instruction. To individualized instruction is to apply psychometric instruments to determine the learning style/study habits of students and to liaise with specialists in educational technology to produce instruction requires certain conditions (facilities) for actualization. Some of these facilities include spaces and their infrastructure, educational software on different lectures supported by appropriate hardware and personnel.

Major disadvantage of still picture is the fact that it tends to present all the contents at once. This holistic presentation denies the opportunity for details. The frigidity of images / lack of change or movement can be a handicap.

\section{Projected still pictures}

Projected pictures come in the form of slides, OHP, filmstrips, microfiche, etc. The pictures are in the 'negative' form after development. It is this 'negative' format that is fitted into a projector for projection while, the flat opaque picture is printed from the negative onto a printing paper. Examples of projected still pictures are slides, filmstrip, over head transparencies, microfiche, microfilm, etc.

\section{Motion pictures}

Motion pictures come in different formats such as $16 \mathrm{~mm}$ films, $8 \mathrm{~mm}$ regular films and $8 \mathrm{~mm}$ super films. Audio materials, video, television materials, and computer assisted instructional packages. These classes of in structural materials need electricity and projectors for their proper use. Together with audio materials, video, television materials, and computer assisted instructional packages; they constitute the high cost, second generation instructional materials. The use of multimedia learning objects in educational setting has been the subject of much interest in recent years.

During recent years in developed countries, education has experienced important progress with respect to the resources used for lecturing. Techniques have changed from traditional blackboard methods to the use of projector transparencies and, later on, the use of video projector and power point, to present the content of the lessons. Nowadays, the use of these technologies has become more common and modern technologies have led to the development of education mainly based on information technology and communication. And since it is no longer in dispute that learning takes place through these educational media materials, the Nigerian government and their teachers should cast away their doubts and apathy about their usefulness and provide the materials and the relevant skills to apply them.

Teachers must be prepared to adapt their teaching styles and methods according to new developments in technology in education, especially since they will inevitably have repercussions in the classroom. Dike (2002) stated some instructional materials in various subjects as follows:

16mm Films - Chemistry 
- Acid base indicators (19minutes, colour). This film uses the proton acceptor theory to interpret the experimental behaviour of acid-base indicators;

- Acids, bases and salts (21 minutes, B and W). This film shows the important properties of acid, bases and salts and their preparations and usage.

$16 \mathrm{~mm}$ Films - Biology

- Adapting to changes in nature (10 minutes, colour).Through observations of the Gray Squirrel preparing for the winter, a horned toad living in the dry desert, a tree reacting to changes in seasons, a flower reacting to nightfall, a Robin raising its young one and the instinct of a monarch butterfly, we learn how animals and plants adapt to changes in nature;

- Adaptive Radiation, the Mollusks (18 minutes, colour). This film illustrates the principles of adaptive radiation by showing how the typical molluscan characteristics are modified in each of the classes.

\section{$16 \mathrm{~mm}$ Films - Mathematics}

- Adding to make seven (10 minutes, colour). This film helps students to develop an understanding of sets and the commutative principle of addition. It shows that sets one and two can be joined in reverse order and the result will still be set three;

- Addition and its properties (30 minutes, colour). This question in this film is: what is meant by the union of a pair of sets, how can the sum of a pair of whole numbers be defined in terms of sets, what are some properties of addition and what does an expression such as " 2 x 3", mean?

\section{Record and Filmstrips Set}

- Eskimos of St. Lawrence Island. Contains three filmstrips. Topics include: hunting with the Eskimos village Three records are also included;

- Far away places: Amazon River, Greenland and Hong Kong. This set contains six filmstrips, three records and three teacher guides. Locations explored are river body (Amazon River), Dragon Kite (Hong Kong) and children of the North Pole (Greenland).

\section{Audio materials}

Audio materials come in the form radio, cassette, record discs and recently, compact discs (CDs). Lesson can be recorded in these formats for group presentation or for use by individual students at their own pace.

\section{3- Dimensional materials}

Models, mock-ups, diorama, real things or realia, artifacts, etc, represent this class of instructional material. They are called 3-dimensional because they have length, width and depth. This third dimension of depth makes it possible for users to see the internal composition of a material. This is unlike the two-dimensional material produced on a cardboard sheet of paper. A creative teacher can put three-dimensional materials to several uses in the classroom. A model is a replica of the real thing. We can improvise a model of a fish, a boat, a radio etc. A mock-up is a model whose parts can be dismantled and manipulated. We can have a mock-up of the human ear. Children can be asked to dismantle such a mock-up and to re-assemble them correctly. A diorama is used to reenact a past event. It is built by assembling different types of models in order to unfold a story. Every Christmas, Christians reenact the birth of Christ in supermarkets and churches by producing a diorama of this event. We can use a diorama to reenact a equatorial rain forest region of the world with appropriate fauna, flora and soil types.

\section{Computer based instructional materials}

Globalization and the use of new technologies in education are leading to a new qualitative and quantitatively way of learning. The process of learning can become significantly richer as students/teachers have access to new types of information and the new way this information can be manipulated by means of computational tools. In the classroom, computer can be used for drill and practice for tutorials, for games and simulations. Computer is useful in analyzing research data, for managing learning and other school activities. Teachers must be prepared to adapt their teaching styles and methods according to new developments in technology in education. For instance the use of sensors attached to computer is of widespread use in research in sciences for some decades now. They allow the automation of data acquisition and make it available for offline analysis with computer tools. With the development and popularization of the personal computer, the same use in teaching laboratories became possible. Some years ago, it was necessary to use dedicated hardware and spend a great amount of time writing computer code for experiment.

Today, easy to use equipment and soft ware are available, providing general tools for different sorts of experiments, and making Microcomputer Based Laboratory systems an interesting option to equip teaching of sciences, both at the undergraduate and graduate levels. With the adequate sensors, the system can become a programmable digital voltmeter, a digital oscilloscope or a digital dynamometer with data logging capability, for example. The software, not only controls the interface for the data acquisition, but also allows their presentation through graphics and tables, as well as their analysis with several tools, depending on the system

However, the list of instructional materials that a teacher can use to improve the quality of instruction is inexhaustible. The teacher's level of resourcefulness, creativity and imagination is in fact, unlimited. It is a fact that classroom learning depends on effective communication, skillful application of the several techniques and materials for learning. Indeed, globalization has generated new necessities, ideologies and ways to understand communications. There is evidence that the use of new technologies in learning is less effective or even ineffective when the learning objectives are unclear and the focus of the technology is diffuse. In Nigeria, these aspects could be, in some cases generating false expectations.

\section{The pedagogical use of instructional materials}

The relevance of instructional materials in the teaching-learning process cannot be understated. The interest on teacher training is obvious. A strong scientific formation and training in didactics are crucial and also 
fundamental is to know about learning and developmental processes and how to manage all of them in a classroom. Producing instructional programs and providing the machinery for using them do not constitute instructional materials or educational technology. The materials produced have to be effectively managed for their usefulness to be realized. The selection of instructional materials depends on the topic under consideration and its instructional objectives, the nature of the learner and the teaching philosophy of a school. Dike (1989) states that educational technology deals with the provision of alternative instructional materials for effective teaching and learning in which learning takes place at three levels namely: at the level of direct experience; at the iconic (image or pictorial) level; and at the symbolic level

Hence each learner has different interpretation to a phenomenon depending on some variables such as sex, age, education, economic, social or cultural factors. Instructional materials therefore can be described as being useful to:

- a systematic arrangement of instruction in such a way that learning is facilitated;

- help the learners to interact individually or in groups for learning to take place;

- easy delivery of a lesson by the teacher;

- helping learners to learn at their own pace;

- helping learners to learn faster and better;

- broaden students' knowledge and level of understanding.

Teaching is about facilitating students' learning process. Taking a look at the learner, identifying his needs, interests and abilities and bearing these variables in mind when designing and producing instructional materials are necessary. Instructional materials then can be described as a systematic arrangement of instruction in such a way that, learning is facilitated. Instructional design should look at the subject matter that is to be learnt and specifying objectives in behavioral terms. It thus should take into account the learning conditions, applying learning and other principles in the planning, designing, producing and evaluating of instructional materials and programs. The design should be based on knowledge of how human beings learn, adopting effective and efficient management strategies for the utilization of such materials. Instructional materials when properly used have illustrative and motivational properties that make learning memorable and entertaining.

\section{Instructional materials for the learners' needs}

For the teachers engagement in the development and delivery of content through the use of instructional materials has been an exciting and challenging journey. The need to develop an effective instruction is to ensure that no learner is educationally disadvantaged, that all learners have equal opportunities to use their individual talent to the fullest degree. It is an opportunity to educate teachers and learners from the traditional teaching and learning processes to an instructional experience based on a wider ranged of carefully planned learning experience.

The use of any methodological strategy requires previous planning work. Instructional design calls for a thorough pre-planning. It involves preparing a blueprint of instructional development and delivery, utilizing multimedia, multi-disciplinary approaches with the objective of improving the teaching and learning processes. An appropriate use of instructional materials calls for the teacher to have the topic and learning objectives that he/she is searching for clear from the start, at what moment of the lesson they shall be introduce, what is going to be the organization of the learner and the space and times that can be count on, what he/ she demand from the learners, what to evaluate and how, etc.

An important matter, and which has facilitated the implementation of instructional design is the ability of the teacher to determine the learners' needs. Esu et al. (2004) pointed that ordinary word of verbalization has seen to be inadequate for effective teaching because it has failed to deliver the needed objective instruction in schools hence the instructional materials which may be used by the learner to facilitate the acquisition and evaluation of knowledge and skills.

Similarly, Ekpo (2004) declared that instructional materials are often used to compensate for the inadequacies of the sense organs or to reinforce the capacity of the dominant organs. They must be relevant for the realization of the intentions of the curriculum. The teacher must take special care with the explanation of the handling of the tool and its specific recommendations.

The presentation of each objective in a concrete term is considered necessary to employ appropriate sequencing techniques to sequence content and abstracts and applies learning and communication principles to enhance presentation. For instance different instructional materials were designed to cover all the issues included in a B.Ed degree or NCE Integrated science course entitled 'Germination of Seeds'. The topic was divided in four sections to address the instructional objectives as follows: (1) identify the features of a germinating seed; (2) describe the two types of germination; (3) describe the conditions necessary for germination; (4) identify some seeds that a particular condition may affect more or inhibit its germination.

The teacher begins the lecture with a short introduction of the topic that they are going to present in the lecture. This explanation lasts only 1 or 2 minutes. All the instructional materials followed a similar structure. An initial slide with germinating seeds and after different slides with photographs, graphic etc to show different ways of positioning in the process of various seeds germination

On the other hand, diagrams, could be use to explain the two major types of germination (using corn and beans) by identifying what happened to their seed leaf. Presenting the corn and beans seedling to identify and name the features. Thus, the important concept can be shown in a simple way favouring the learning process. The various conditions are necessary for germination. A comparison of germination of a healthy and unhealthy seed in the presence of air, soil moisture, light and in the dark is exhibited.

The teacher points out that light is necessary for some other seeds (e.g., grand rapids lettuce) and may inhibit the germination of other ones (e.g., some varieties of onions). However, the instructional materials not only include photographs or diagrams, but also text, equations or chemical reactions. In the following snapshots, chemical 
reactions could be used to explain the embryo in the seed resumes growths when favourable environmental conditions such as adequate water, normal atmospheric composition of gases $\left(21 \% \mathrm{O}_{2}, 78 \% \mathrm{~N}_{2}, 0.03 \% \mathrm{CO}_{2}\right)$ and favourable temperature are available that determines conditions necessary for germination. Also the issue of seed and stand establishment in a polluted environment, the students can see what substances are involved in the reaction and what the resulting effects are.

It is necessary to identify that different instructional materials were useful because they could be used to explain evolution process, ranges of values, show different plot, such as bar chart or pie chart, etc. Proper planning is necessary to ensure real integration of these materials to achieve the desired instructional goal

To improve the pedagogy of different learners' needs, the use of instructional materials for the students in the colleges of education in Nigeria is indispensable. A shift will be necessary from what has traditionally been experienced in the Nigeria classrooms toward more inquiry teaching practices using instructional materials, which facilitated teaching for meaningful learning. This calls for teacher's resourcefulness and improvisation where there is shortage of instructional materials. The teacher may decide to improvise or visit the sites for some topics.

\section{Conclusion}

Instructional materials offer student-teachers the possibility of glimpsing into real classrooms and reflect upon what is going on. They learn, retain and apply new facts and skills as they actively involved in the teachinglearning process. There is need for both teachers and teachers trainees to be technologically aware and competent. Unfortunately, many teachers are frustrated by their inability to find the right type of instructional materials to use to concretize a concept as a result of poor level of training and utilization of instructional materials. For successful integration of instructional materials into classroom teaching, teachers have to optimize the use of instructional materials available to them. It is imperative to make available to teachers that a large resource of appropriate and adaptable instructional materials. However, these materials have to not only be guided by technological advancements but to suit the teachers' and learners' experiences and needs.

The action should focus not only on the instrumental management but on the various technological tools; put special emphasis on educational development and methodological integration of technology resources. The instructional objectives have to determine the instructional materials. Instructional materials must be directly relevant to the content of the lesson. It has to be integrated with the teachers approach and subject presentation.

Faced with growing need to integrate instructional materials into teaching, the government should work to provide the schools with necessary infrastructure to allow these changes. And to offer the teachers enough training that would help them not only to adapt to changes, but also to optimize the use of these materials in their day to day teaching. The education authorities should concentrate their efforts on supporting applied training in the use of instructional materials in schools. To improve the level of confidence that teachers have in the use of instructional materials in teaching. This study is the contribution to the goal.

\section{References}

Agina-Obu, T., 2005. "The relevance of instructional materials in teaching and learning," in: Robert-Okah, I. and Uzoeshi, K. (Eds.), Theory and practice of teaching, Port Harcourt: Harey Publication.

Agun, I., 1988. "Learning materials towards education in the year 2000,'Journal of Educational Media Technology, Vol.1(4), pp.498-521.

Bruner, J., 1973.The process of education, Cambridge: Harvard University Press.

Dike, H., 1999. A textbook of educational technology, Port Harcourt, CAPIC Publishers

Dike, H., 2002. Alternative teaching approaches for social studies, With implications for social science and sciences, Port Harcourt, CAPIIC Publishers.

Ekpo, O., 2004. Instructional strategies and the challenges of implementing school curriculum in Nigeria, lead paper presented at 17th annual conference of the curriculum organization of Nigeria (CON) held at University of Uyo, Uyo, Akwa Ibom State, 14th-17th September.

Esu, A., Enukoha, O., Umorem, G., 2004. Curriculum development in Nigeria for colleges and universities. Owerri: Whyte and Whyte Publishers.

Ikerionwu, J., 2000. "Importance of aids and resources in classroom teaching," in: Perspective of classroom teaching, Oyeneyin, A. (Ed.), Abuja: Martmonic Investment Ltd.

Johnson, H., 1989. "Relevant instructional materials in family life education for Nigerian secondary schools," A paper delivered at the workshop on population/family life education material development, organized by NERDC/CEDPA/Johnson- Hopalang University 23rd - 29rd April at Dubar Hotel, Lagos.

Obanya, P., 1989. Potentialities of educational materials in Africa, in: Inter-learning of Educational Innovation, Dakar: UNESCO- BREDA, pp.55-64. 